\title{
Estimates of recent and historical effective population size in turbot, seabream, seabass and carp selective breeding programmes
}

\author{
María Saura ${ }^{1 *} \mathbb{D}$, Armando Caballero², Enrique Santiago ${ }^{3}$, Almudena Fernández ${ }^{1}$, Elisabeth Morales-González , \\ Jesús Fernández ${ }^{1}$, Santiago Cabaleiro ${ }^{4}$, Adrián Millán ${ }^{5}$, Paulino Martínez ${ }^{6}$, Christos Palaiokostas ${ }^{7}$, \\ Martin Kocour ${ }^{8}$, Muhammad L. Aslam ${ }^{9}$, Ross D. Houston ${ }^{7}$, Martin Prchal ${ }^{8}$, Luca Bargelloni ${ }^{10}$, Kostas Tzokas ${ }^{11}$, \\ Pierrick Haffray ${ }^{12}$, Jean-Sebastien Bruant ${ }^{13}$ and Beatriz Villanueva ${ }^{1}$
}

\begin{abstract}
Background: The high fecundity of fish species allows intense selection to be practised and therefore leads to fast genetic gains. Based on this, numerous selective breeding programmes have been started in Europe in the last decades, but in general, little is known about how the base populations of breeders have been built. Such knowledge is important because base populations can be created from very few individuals, which can lead to small effective population sizes and associated reductions in genetic variability. In this study, we used genomic information that was recently made available for turbot (Scophthalmus maximus), gilthead seabream (Sparus aurata), European seabass (Dicentrarchus labrax) and common carp (Cyprinus carpio) to obtain accurate estimates of the effective size for commercial populations.

Methods: Restriction-site associated DNA sequencing data were used to estimate current and historical effective population sizes. We used a novel method that considers the linkage disequilibrium spectrum for the whole range of genetic distances between all pairs of single nucleotide polymorphisms (SNPS), and thus accounts for potential fluctuations in population size over time.

Results: Our results show that the current effective population size for these populations is small (equal to or less than 50 fish), potentially putting the sustainability of the breeding programmes at risk. We have also detected important drops in effective population size about five to nine generations ago, most likely as a result of domestication and the start of selective breeding programmes for these species in Europe.
\end{abstract}

Conclusions: Our findings highlight the need to broaden the genetic composition of the base populations from which selection programmes start, and suggest that measures designed to increase effective population size within all farmed populations analysed here should be implemented in order to manage genetic variability and ensure the sustainability of the breeding programmes.

*Correspondence: saura.maria@inia.es

1 Departamento de Mejora Genética Animal, INIA-CSIC, Ctra. de La Coruña, km 7.5, 28040 Madrid, Spain

Full list of author information is available at the end of the article

\section{Background}

The success of any breeding programme depends critically on how the base population of breeders is built, since the genetic variability that is initially available in the founders will affect the genetic progress achieved in the subsequent selection programme [1-3]. This is original author(s) and the source, provide a link to the Creative Commons licence, and indicate if changes were made. The images or other third party material in this article are included in the article's Creative Commons licence, unless indicated otherwise in a credit line to the material. If material is not included in the article's Creative Commons licence and your intended use is not permitted by statutory regulation or exceeds the permitted use, you will need to obtain permission directly from the copyright holder. To view a copy of this licence, visit http://creativecommons.org/licenses/by/4.0/. The Creative Commons Public Domain Dedication waiver (http://creativeco mmons.org/publicdomain/zero/1.0/) applies to the data made available in this article, unless otherwise stated in a credit line to the data. 
particularly important in aquaculture because, given the high fecundity of fish species, base populations can be created from very few individuals, which would lead to small effective population sizes $\left(N_{e}\right)$ and therefore, to high rates of loss of genetic variability, high rates of inbreeding and restricted long-term selection responses.

With the rapid development of genomic tools, temporal series of $N_{e}$ can be estimated for generations before pedigree recording began. This is of great importance in aquaculture species to determine the impact of domestication on the genetic variability present in the base populations and the potential long-term response to selection. Genomic estimates of $N_{e}$ are obtained based on the linkage disequilibrium (LD) approach [4], and different methods have been developed to estimate this parameter across generations. These methods have assumed that the $N_{e}$ of a particular generation in the past can be estimated from LD between pairs of single nucleotide polymorphisms (SNPs) separated by a specific distance [5]. However, this assumption implies that the demographic events that occurred in that particular generation do not affect subsequent generations, and the method only holds for linear changes in population size [5]. To circumvent this problem, Santiago et al. [6] have recently developed an approach where the LD spectrum for the whole range of recombination rates between all pairs of SNPs is taken into account for estimating $N_{e}$ in consecutive generations, and this allows the detection of drastic changes in population size.

In spite of the importance of estimating $N_{e}$, estimates of this parameter are scarce for most aquaculture species. In this study, we used genomic information that was recently produced for important fish species in European aquaculture (turbot, gilthead seabream, European seabass and common carp) to obtain recent and historical estimates of $N_{e}$ for commercial populations, using the novel method developed by Santiago et al. [6]. These estimates are useful to evaluate the current genetic status of the populations and to identify past changes in $N_{e}$ potentially associated with domestication or with the establishment of selective breeding programmes.

\section{Methods \\ Data}

Data were derived from broodstock (and their offspring) sampled in 2014 from different European breeding programmes for turbot, gilthead seabream, European seabass and common carp within the framework of the FISHBOOST project (www.fishboost.eu) (Table 1). Unrelated broodstock were mated and their offspring were used for different experimental purposes. Genomic information was available for both parents and their offspring. Genotypes were obtained using reduced representation genotyping approaches [specifically RAD sequencing, (RAD-seq)]. The species' linkage maps and reference genomes were used to map the SNPs [7-10]. Details on the number of samples and SNPs available for each population analysed are summarised in Table 1. Genotyping and filtering details are described elsewhere for turbot [7], seabream [8], seabass [9] and carp [10]. Imputation of missing genotypes, which was only performed for turbot, was carried out using the software BEAGLE 4.1 [11].

Turbot samples were obtained from an experimental population of Atlantic origin maintained at CETGA (Aquaculture Cluster of Galicia, Spain) through hierarchical matings. For gilthead seabream, data came from one of the four genetically linked yearly cohorts of the breeding nuclei of the Andromeda Group SL (Greece) and Ferme Marine de Douhet (FMD, France), where the main breeding objectives in the selection programmes are growth and body shape. The Andromeda programme applies mass spawning, while the FMD programme applies partial factorial mating designs [8]. European seabass samples came also from one of the four linked yearly cohorts of the FMD breeding nucleus, where the breeding objectives are growth and body shape. In this programme, partial factorial matings are also applied [9]. Finally, for common carp, samples were obtained from the Amur Mirror carp (Vodňany line), which was recently

Table 1 Description of samples and genomic information for the populations analysed

\begin{tabular}{|c|c|c|c|c|c|c|c|}
\hline Population & $N_{\text {off }}$ & $N_{p a r}(\delta, \uparrow)$ & $n_{s n p}$ & $n_{l g}$ & $\mathrm{cM}$ & $\mathrm{Mb}$ & $d$ \\
\hline Turbot & 1391 & $46(23,23)$ & 18,097 & 22 & 1403 & 568 & 32 \\
\hline Seabream_A & 724 & $117(57,59)$ & 15,184 & 24 & 1406 & $790^{a}$ & 19 \\
\hline Seabream_F & 881 & $107(71,22)$ & 21,701 & 24 & 1970 & $790^{\mathrm{a}}$ & 28 \\
\hline Seabass & 1308 & $65(48,17)$ & 8014 & 24 & $1373^{a}$ & 577 & 14 \\
\hline Carp & 1349 & $60(40,20)$ & 12,311 & 50 & 3944 & $1830^{a}$ & 7 \\
\hline
\end{tabular}

Number of offspring $\left(N_{\text {off }}\right)$ and parents ( $N_{\text {par }}$ including sires and dams) with genotypes available, number of SNPs $\left(n_{\text {snp }}\right)$ and linkage groups $\left(n_{l g}\right)$, genetic $(c M)$ and physical (Mb) genome size and resulting SNP density ( $d$, in SNPs per Mb) for each population

${ }^{\text {a }}$ Estimates taken from the literature ([44] for turbot; [45] for seabream; [46] for seabass; [47] for carp) 
created at the University of South Bohemia in České Budějovice. For this line, $F_{1}$ offspring were obtained from crosses between females from a cultured population (originating from Hungary and Germany) with a mirror phenotype for scaliness and males from a wild population (from the Amur river, Siberia) with a scaly phenotype. The Amur Mirror strain was founded from $\mathrm{F}_{2}$ crosses by selecting offspring that had the mirror phenotype. The population used in this study was obtained by artificial fertilization that involved four blocks of full factorial crosses each comprising five dams and ten sires [10].

\section{Estimation of linkage disequilibrium and effective population size}

Estimates of LD between pairs of loci and temporal estimates of $N_{e}$ were obtained using the software GONE and its auxiliary programs developed by Santiago et al. [6] (available in https://github.com/esrud/GONE). Squared correlations between allele frequencies of pairs of SNPs $\left(r^{2} ;[12]\right)$ were obtained for all pairs of SNPs within each linkage group (chromosome). Category bins for different ranges of genetic distances (in Morgans) between SNPs were built and the average values of $d^{2}$ (the average of $r^{2}$ values between pairs of SNPs weighted by their variance in allele frequences; [13]) were obtained for each bin. The method involves a genetic algorithm to infer the historical series of $N_{e}$ in the population that minimises the sum of the squared differences between the observed values of $d^{2}$ of the bins and those predicted considering different demographic histories. The analyses assumed that phase is unknown and the genetic distances between SNPs were corrected by Haldane's function. For the remaining software options, the default values were used. In order to compare our results with those of other studies, patterns of LD measured as $r^{2}$ across physical distance were represented for the populations for which the physical position of SNPs was available on the reference genome assemblies (i.e. turbot GCA_003186165.1 and seabass GCA_000689215).

For the sake of comparison, temporal estimates of ancestral $N_{e}$ were also obtained using the previous method of Hayes et al. [5] as implemented by Saura et al. [14]. Although both the GONE method and that of Hayes et al. [5] are based on the well known relationship between LD and $N_{e}$ [4], the main difference between them is that the former assumes constant $N_{e}$ or linear changes in $N_{e}$.

\section{Results}

The pattern of LD decay with physical distance that was computed with offspring data for turbot and seabass is represented in Fig. 1. Overall, the average LD $\left(r^{2}\right)$ between SNPs separated by short distances $(<0.01 \mathrm{~kb})$ was moderately low ( 0.15 for turbot and 0.24 for seabass) and decreased rapidly with physical distance. The average $r^{2}$ was reduced by half in both cases for distances shorter than $5 \mathrm{~kb}$.

Estimates of recent $N_{e}$ were equal to or less than 50 fish in all cases. When using offspring data, $N_{e}$ of 31 for turbot, 46 for seabream_A, 32 for seabream_F, 40 for seabass and 33 for carp were found, and when using parents data, the corresponding values were $26,50,30,32$ and 15 , respectively.

Estimates of historical $N_{e}$ were larger than 1000 fish for about 20 generations ago in all species. However, important drops were observed about five generations ago for turbot and seabream and about eight to nine generations ago for seabass, using data from parents or from offspring (Fig. 2 and see Additional file 1: Fig. S1). The two populations of seabream showed a similar pattern of $N_{e}$ decay. Estimates of ancestral $N_{e}$ are not provided for carp since the Amur Mirror strain comes originally from crosses of several strains, and under a scenario of strong and recent population admixture, the method to estimate historical $N_{e}$ is not conceptually applicable. However, estimates of contemporary $N_{e}$ can be obtained in this case, although the estimates are likely to be biased downwards because of population admixture [15].

The LD method of Hayes et al. [5] led to linear trends in historical $N_{e}$, as expected (see Additional file 2: Fig. S2), which contrasts with the drastic drops shown in Fig. 2. Historical values estimated with this method for the earliest generation shown (generation 100) were smaller than 1000 individuals, i.e. much smaller than those obtained by GONE in Fig. 2. However, recent $N_{e}$ values with the same method (44 for turbot, 33 for seabass, 51 for seabream_A, and 49 for seabass_F) were of the same order of magnitude as those obtained with the method of Santiago et al. [6] and are shown in Fig. 2.

\section{Discussion}

In this study, recent and historical $N_{e}$ estimates were obtained for farmed populations of important European aquaculture species (turbot, gilthead seabream, European seabass and common carp), using genome-wide SNP data from RAD-seq, and a novel accurate method based on LD measures [6]. Our results revealed that recent $N_{e}$ for all the analysed populations were small and that important drops in ancestral $N_{e}$ occurred in these populations about five to nine generations ago.

Recent $N_{e}$ estimates for all the analysed populations were equal to or less than 50 fish. A value around 50 is considered to fit the minimum value recommended to avoid severe inbreeding depression and retain fitness in 

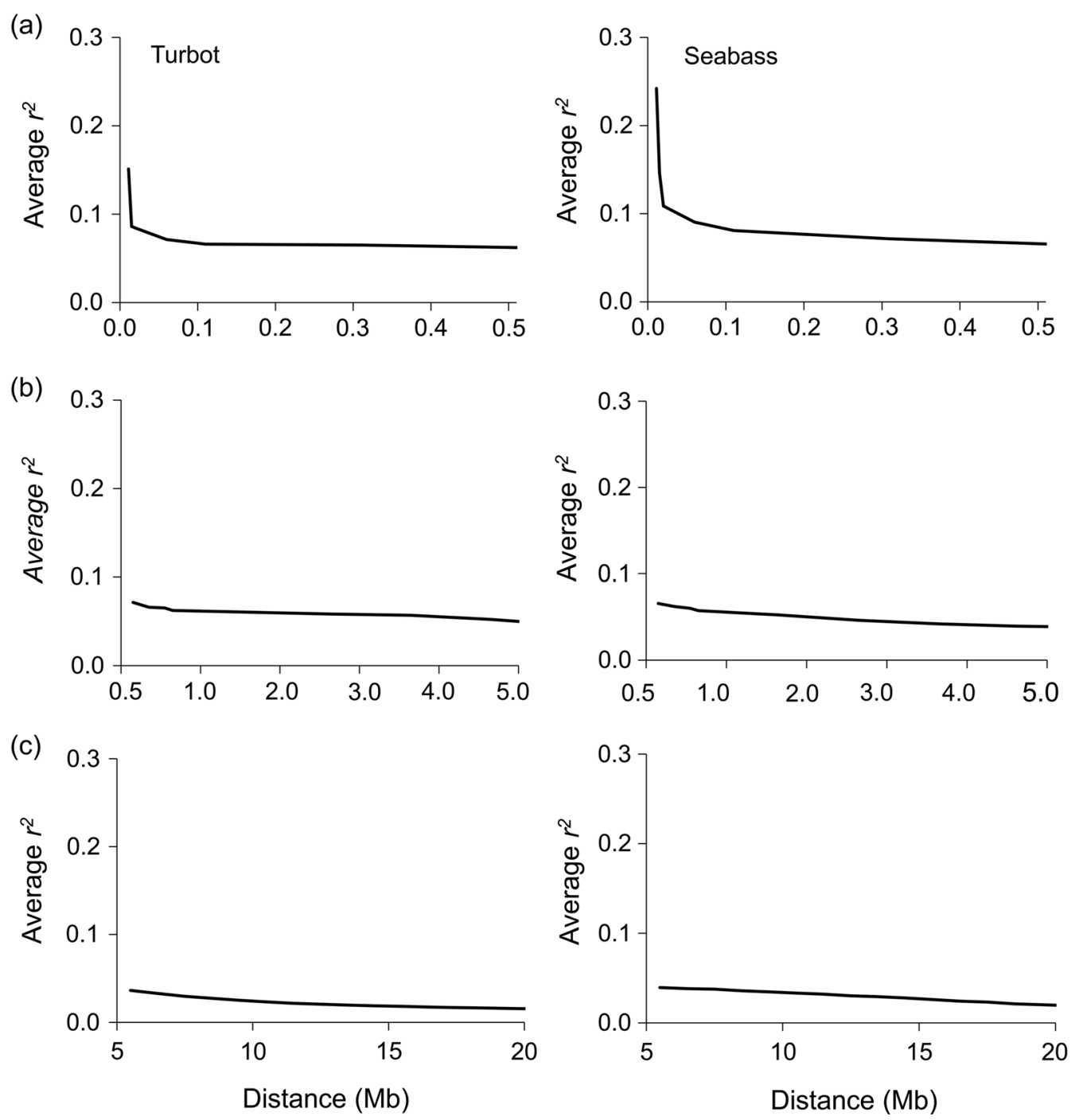

Fig. 1 Decay of average linkage disequilibrium across chromosomes measured as $r^{2}$ against physical distance. Physical distance in terms of fragment length is indicated in $\mathrm{Mb}$ for the species for which a physical map is available; i.e. turbot (left panels) and seabass (right panels). Three different distance categories are represented: a from 0.0 to $0.5 \mathrm{Mb}$; b from 0.5 to $5 \mathrm{Mb}$; c from 5 to $20 \mathrm{Mb}$

the short-term [16-18]. However, our $N_{e}$ estimates for seabream and seabass could be slightly underestimated given that the data used came from breeding schemes with overlapping generations and the method asumes discrete generations $[6,19]$.

In general, the magnitude of our recent estimates of $N_{e}$ was within the range of those found in other farmed fish populations of different species [20-30], although there are exceptions [31]. For instance, the estimate of $N_{e}$ in the GIFT (Genetically Improved Farmed Tilapia) selection programme in which the creation of the base population was carefully planned, was equal to 88 after seven generations of selection for growth rate [31]. The small estimates of $N_{e}$ obtained for the farmed populations analysed here contrast with the large estimates $(>1000)$ found for wild populations of turbot, seabass and seabream [3234]). Although estimates of $N_{e}$ for the wild common carp are not available, genetic variability analyses have shown that they are smaller in farmed than in wild strains [35, 36].

Estimates of historical $N_{e}$ for all the analysed populations revealed important drops occurring about five to nine generations ago. We obtained similar results using data from the reduced number of parental samples or from the more extensive number of offspring samples (Fig. 2). The power of the method to detect fluctuations in $N_{e}$ is proportional to the product of the sample size and the square root of the number of markers divided by 

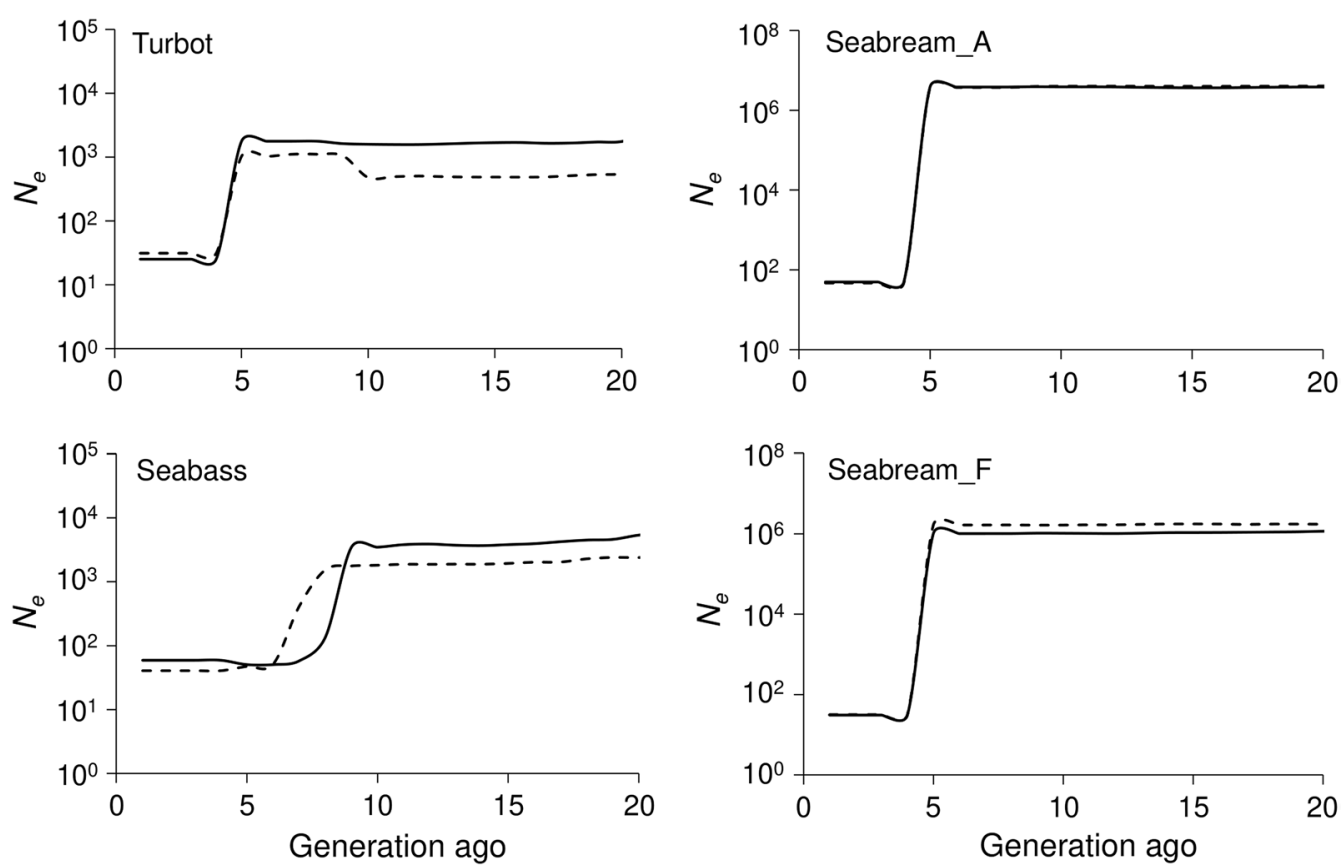

Fig. 2 Estimates of $N_{e}$ (logarithmic scale) across the last 20 generations for each population analysed. Straight lines represent estimates obtained using data from parents and dashed lines represent estimates obtained using data from offspring

$N_{e}$, and the minimum value to ensure accurate estimations of $N_{e}$ is 100 [6]. Using parental samples, the value was much larger than 100, and thus estimates obtained from parents were as reliable as those obtained from offspring.

A drop in $N_{e}$ and the consequent drop in genetic variability in farmed populations can occur during the establishment of the base population (founder effect) but also in subsequent generations of selection if there is no optimal inbreeding control. Some caution must be taken in the interpretation of the drops observed as they could also be a consequence of population admixture or of the use of inaccurate genetic maps [6]. Nevertheless, our results are highly consistent with the information about the origin of broodstock and how these programmes have been run. Although limited, the available information suggests that the domestication of turbot, gilthead seabream and European seabass started around the 1970s, and that selective breeding programmes for increasing growth rate started in the 1990s [37], with approximately four to six generations of selection to date for the populations analysed here. Under this broad context, our estimates of historical $N_{e}$ suggest that the combination of both domestication and the start of selection programmes is the most likely explanation for the important recent drops inferred in the populations analysed. Both events may have occurred too close in time to be disentangled by the method.
Our results reflect a moderately low LD between SNPs that are separated by very short distances in turbot and seabass populations. In addition, a very fast $\mathrm{LD}$ decay with physical distance was observed in both populations. In fact, $r^{2}$ decreased by half at distances shorter than $0.02 \mathrm{Mb}$ and it was maintained when the distance increased by one order of magnitude. At distances longer than $10 \mathrm{Mb}, r^{2}$ reached values lower than 0.05. Similar LD values have been reported for coho salmon [29] and Nile tilapia [38] at short distances but the rate of decrease in LD was much slower than those observed here for turbot and seabass. Much higher values of LD (>twofold for short distances) have been reported in farmed populations of Atlantic salmon [28, 39, 40] and rainbow trout [30], with also LD remaining higher over much longer distances. These results may suggest that higher LD values are observed in populations with a longer history of artificial selection.

As already mentioned, an important limitation of the LD method of Hayes et al. [5] to estimate historical $N_{e}$ is that it only holds for linear changes in population size. Indeed, previous studies applying this method have observed linear trends in $N_{e}$ over time [28-31], as we observed when reanalysing our data applying this method (see Additional file 2: Fig. S2). As reflected in our results, the method by Santiago et al. [6] provides in this case, a more precise view of the drastic changes in the historical $N_{e}$, such as those observed in Fig. 2. Another difference 
between the results of the two methods concerns the large discrepancy between the historical estimates of $N_{e}$ (see Additional file 1: Fig. S1 and Additional file 2: Fig. S2). In order to shed some light on this issue, we carried out computer simulations under a scenario that mimics the pattern observed in Fig. 2 (see Additional file 3: Fig. S3 for results and simulation details). In the simulations, a large population with a constant size $N$ of 1000 or 10,000 suddenly drops to $N=100$ or 50 individuals in the last ten or five generations, respectively. We repeated this simulation 20 times and carried out analyses with the methods of Santiago et al. [6] (using GONE) and Hayes et al. [5]. The simulations show that the method of Hayes et al. [5] does not reflect the sudden drop in population size, and that it gives very downwardly biased estimates of the historical size. The simulations also show that the ancestral $N_{e}$ obtained by GONE can be overestimated, particularly when the size of the ancestral population is large. Thus, the large observed values of ancestral $N_{e}$ shown in Fig. 2 and Additional file 2: Fig S2 should be taken with caution, since they can be overestimations. In any case, GONE is able to detect the drastic change in $N_{e}$ as reflected in both figures.

\section{Conclusions}

In summary, our results suggest that the current $N_{e}$ of the commercial populations analysed here are, in general, below the critical value of 50 individuals that is recommended to ensure short-term sustainability of selection programmes. Series of historical $N_{e}$ reveal important drops probably due to domestication and the start of breeding programmes. Our findings highlight the need for broadening the genetic composition of base populations from which selection programmes start and suggest that measures to increase $N_{e}$ within all the farmed populations analysed here should be implemented. These measures include increasing the number of parents selected, conducting artificial fertilization and applying single-pair rather than mass spawning [41], and if possible implementing optimal contribution selection [42, 43], to maximise genetic gain while restricting the rate of inbreeding. In cases where these interventions are not sufficient to increase $N_{e}$ above the critical value, another option could be to interchange genetic material from different genetically improved stocks.

\section{Supplementary Information}

The online version contains supplementary material available at https://doi. org/10.1186/s12711-021-00680-9.

Additional file 1. Estimates of $N_{e}$ (logarithmic scale) across the last 100 generations for each population analysed. Straight lines represent estimates obtained using data from parents and dashed lines represent estimates obtained using data from offspring.

Additional file 2. Estimates of $N_{e}$ (logarithmic scale) obtained with the LD method of Hayes et al. [5] across the last 100 generations for each population analysed.

Additional file 3. Estimates of $N_{e}$ (logarithmic scale) obtained by computer simulations with the LD methods of Hayes et al. [5] and Santiago et al. [6], using the software SLiM3 [48].

\section{Acknowledgements}

The authors thank two anonymous referees and the editors Helene Hayes, Jack Dekkers and Nathalie Saux-Nogues for useful comments. They also gratefully acknowledge the computing time granted by the Centro de Supercomputación de Galicia (CESGA) and for their computing support on the supercomputer Finis Terrae II (ft2.cesga.es).

\section{Authors' contributions}

MS performed the analyses and wrote the first draft of the manuscript. ES and $\mathrm{AC}$ developed the method and software used and contributed to the analyses. AF and EM-G contributed to the analyses. SC, PM, AM, CP, MK, MLA, $\mathrm{RH}, \mathrm{MP}, \mathrm{LB}, \mathrm{TK}, \mathrm{J}-\mathrm{SB}, \mathrm{PH}$ provided data. BV and JF conceived and designed the study. AC carried out the computer simulations and AC and MS analysed the results. All authors contributed to the discussion of results and the edition of the revised manuscript. All authors read and approved the final manuscript.

\section{Funding}

This work was supported by the European Union's Seventh Framework Programme (KBBE.2013.1.2-659 10 under Grant Agreement No. 613611 FISHBOOST project), the European Commission Horizon 2020 (H2020) Framework Programme through grant agreement no 727315 MedAID project (Mediterranean Aquaculture Integrated Development), by Ministerio de Ciencia e Innovación (CGL2016-75904-C2), MCIN/AEI/https://doi.org/10. 13039/501100011033 (PID2020-114426GB-C22 and PID2020-114426GB-C2), Xunta de Galicia (GRC, ED431C 2020-05) and Centro singular de investigación de Galicia accreditation 2019-2022, and the European Union (European Regional Development Fund-ERDF), Fondos Feder "Unha maneira de facer Europa". MK and MP were also supported by Ministry of Education, Youth and Sports of the Czech Republic—project Biodiverzity (CZ.02.1.01/0.0/0.0/16_ 025/0007370). The Roslin Institute was partly funded by Biotechnology and Biological Sciences Research Council Institute Strategic Programme grants (BBS/E/D/20241866, BBS/E/D/20002172 and BBS/E/D/20002174).

\section{Availability of data and materials}

The aligned reads for carp in the format of bam files were deposited in the National Centre for Biotechnology Information (NCBI) repository under project ID PRJNA414021. For seabass, the sequence reads were deposited at the NCBI Sequence Read Archive (SRA) under the accession number PRJNA407892.

\section{Declarations}

\section{Ethics approval and consent to participate}

Turbot data were obtained in accordance with the recommendations of the ethical regulations and with the approvement of Xunta de Galicia (registered under the code ES150730055401/16/PROD.VET.047ROD.01). Seabass data were obtained in accordance with the recommendations of ANSES/ ENVA/UPC no. 16, authorized by the "Ministère de l'Education Nationale, de I'Enseignement Supérieur et de la Recherche", under number 29/01/13-5. The approval of the seabream experiment was taken from the Istituto Zooprofilattico Sperimentale delle Venezie animal-welfare body and Ethic commission (Opinion no. 15/2013 of the 12 September 2013), authorized by the Italian Ministry of Health (Law decree no. 135/2014-B of the 28th March 2014), according to Directive 2010/63/EU on the protection of animals used for scientific purposes. Carp data were obtained in accordance with the law on the protection of animals against cruelty (Act No. 246/1992 Coll. of the Czech Republic) and approved by Institutional Animal Care and Use Committee (IACUC). 


\section{Consent for publication \\ Not applicable.}

\section{Competing interests}

The authors declare that they have no competing interests.

\section{Author details}

1 Departamento de Mejora Genética Animal, INIA-CSIC, Ctra. de La Coruña, km 7.5, 28040 Madrid, Spain. ${ }^{2}$ Centro de Investigación Mariña, Facultade de Bioloxía, Universidade de Vigo, 36310 Vigo, Spain. ${ }^{3}$ Departamento de Biología Funcional, Universidad de Oviedo, C/ Julián Clavería s/n, 33006 Oviedo, Spain. ${ }^{4}$ CETGA, Cluster de Acuicultura de Galicia, Punta do Couso s/n, 15695 Aguiño-Ribeira, Spain. ${ }^{5}$ Geneaqua, 27002 Lugo, Spain. ${ }^{6}$ Departament of Zoology, Genetics and Physical Anthropology, Universidade de Santiago de Compostela, 27002 Lugo, Spain. ${ }^{7}$ The Roslin Institute and Royal (Dick) School of Veterinary Studies, University of Edinburgh, Easter Bush, Midlothian EH25 9RG, UK. ${ }^{8}$ South Bohemian Research Center of Aquaculture and Biodiversity of Hydrocenoses, Faculty of Fisheries and Protection of Waters, University of South Bohemia in České Budějovice, Zátiší 728/II, 38925 Vodňany, Czech Republic. ${ }^{9}$ Nofima AS, P.O. Box 210, 1431 Ås, Norway. ${ }^{10}$ Universitá degli Studi di Padova, Via 8 Febbraio 1848, 2, 35122 Padova, PD, Italy. ${ }^{11}$ Andromeda Group SA, Leof. Lavriou 99, 19002 Peania, Greece. ${ }^{12}$ SYSAAF, Station LPGP/INRAE, Campus de Beaulieu, 35042 Rennes, France. ${ }^{13}$ Ferme Marine De Douhet, Route du Douhet, 17840 La Brée-les-Bains, France.

Received: 1 February 2021 Accepted: 22 October 2021

Published online: 06 November 2021

\section{References}

1. Holtsmark M, Klemetsdal G, Sonesson AK, Woolliams JA. Establishing a base population for a breeding program in aquaculture, from multiple subpopulations, differentiated by genetic drift: I effects of the number of subpopulations, heritability and mating strategies using optimum contribution selection. Aquaculture. 2008;274:232-40.

2. Holtsmark M, Klemetsdal G, Sonesson AK, Woolliams JA. Establishing a base population for a breeding program in aquaculture, from multiple subpopulations, differentiated by genetic drift: II sensitivity to assumptions on the additive genetic relationships of base animals. Aquaculture. 2008;274:241-6

3. Fernández J, Toro MA, Sonesson AK, Villanueva B. Optimizing the creation of base populations for aquaculture breeding programs using phenotypic and genomic data and its consequences on genetic progress. Front Genet. 2014;5:e414.

4. Hill WG. Estimation of effective population size from data on linkage disequilibrium. Genet Res. 1981;38:209-16.

5. Hayes BJ, Visscher PM, McPartlan HC, Goddard ME. Novel multilocus measure of linkage disequilibrium to estimate past effective population size. Genome Res. 2003:13:635-43.

6. Santiago E, Novo I, Pardiñas AF, Saura M, Wang J, Caballero A. Recent demographic history inferred by high-resolution analysis of linkage disequilibrium. Mol Biol Evol. 2020;37:3642-53.

7. Maroso F, Hermida M, Millán A, Blanco A, Saura M, et al. Highly dense linkage maps from 31 full-sibling families of turbot (Scophtahlmus maximus) provide insights into recombination patterns and chromosome rearrangements throughout a newly refined genome assembly. DNA Res. 2018;25:439-50

8. Aslam ML, Carraro R, Bestin A, Cariou S, Sonesson AK, Bruant J-S, et al. Genetics of resistance to photobacteriosis in gilthead sea bream (Sparus aurata) using 2b-RAD sequencing. BMC Genet. 2018;19:43.

9. Palaiokostas C, Cariou S, Bestin A, Bruant J-S, Haffray P, Morin T, et al. Genome-wide association and genomic prediction of resistance to viral nervous necrosis in European sea bass (Dicentrarchus labrax) using RAD sequencing. Genet Sel Evol. 2018;50:30.

10. Palaiokostas C, Robledo D, Vesely T, Prchal M, Pokorova D, Piacknova V, et al. Mapping and sequencing of a significant quantitative trait locus affecting resistance to Koi herpesvirus in common carp. G3 (Bethesda). 2018;8:3507-13.

11. Browning SR, Browning BL. Haplotype phasing: existing methods and new developments. Nat Rev Genet. 2011;12:703-14.
12. Hill WG, Robertson A. Linkage disequilibrium in finite populations. Theor Appl Genet. 1968;38:226-31.

13. Ohta T, Kimura M. Linkage disequilibrium due to random genetic drift. Genet Res. 1969;13:47-55.

14. Saura M, Tenesa A, Woolliams JA, Fernández A, Villanueva B. Evaluation of the linkage-disequilibrium method for the estimation of effective population size when generations overlap: an empirical case. BMC Genomics. 2015;16:922.

15. Waples RS, England PR. Estimating contemporary effective population size on the basis of linkage disequilibrium in the face of migration. Genetics. 2011;189:633-44.

16. Frankham R, Ballou JD, Briscoe DA. Introduction to conservation genetics. Cambridge: Cambridge University Press; 2002

17. Frankham R, Bradshaw CJA, Brook BW. Genetics in conservation management: revised recommendations for the 50/500 rules, Red List criteria and population viability analyses. Biol Conserv. 2014;170:56-63.

18. Caballero A, Bravo I, Wang J. Inbreeding load and purging: implications for the short-term survival and the conservation management of small populations. Heredity (Edinburgh). 2017;118:177-85.

19. Waples RS, Antao T, Luikart G. Effects of overlapping generations on linkage disequilibrium estimates of effective population size. Genetics. 2014; 197:769-80.

20. Brown TC, Woolliams JA, McAndrew BJ. Factors influencing effective population size in commercial populations of gilthead seabream, Sparus aurata. Aquaculture. 2005;247:219-25.

21. Borrell V, Gallego V, García-Fernández C, Mazzeo I, Pérez L, Asturaino JF, et al. Assessment of parental contributions to fast- and slow-growing progenies in the sea bream Sparus aurata L. using a new multiplex PCR. Aquaculture. 2011;314:58-65.

22. Šegvić-Bubić T, Grubišić L, Trumbić Ž, Stanić R, Ljubković J, Maršić-Lučić $J$, et al. Genetic characterization of wild and farmed European seabass in the Adriatic sea: assessment of farmed escapees using a Bayesian approach. ICES J Mar Sci. 2017;74:369-78.

23. Eknath A, Doyle RW. Effective population size and rate of inbreeding in aquaculture of Indian major carps. Aquaculture. 1990;85:293-305.

24. Gallardo JA, García X, Lhorente JP, Neira R. Inbreeding and inbreeding depression of female reproductive traits in two populations of Coho salmon selected using BLUP predictors of breeding values. Aquaculture 2004;234:111-22.

25. Yáñez JM, Bassini LN, Filp M, Lhorente JP, Ponzoni R, Neira R. Inbreeding and effective population size in a coho salmon (Oncorhynchus kisutch) breeding nucleus in Chile. Aquaculture. 2014:420:515-19.

26. Su G-S, Liljedahl L-E, Gall GAE. Effects of inbreeding on growth and reproductive traits in rainbow trout (Oncorhynchus mykiss). Aquaculture. 1996;142:139-48.

27. Pante MA, Gjerde B, McMillan I. Effect of inbreeding on body weight at harvest in rainbow trout, Oncorhynchus mykiss. Aquaculture. 2001;192:201-11.

28. Barría A, López ME, Yoshida G, Carvalheiro R, Lhhorente JP, Yáñez JM. Population genomic structure and genome-wide linkage disequilibrium in farmed Atlantic salmon (Salmo salar L.) using dense SNP genotypes. Front Genet. 2018;9:649

29. Barría A, Christensen KA, Yoshida G, Jedlicki A, Leong JS, Rondeau EB, et al Whole genome linkage disequilibrium and effective population size in a coho Salmon (Oncorhynchus kisutch) breeding population using a highdensity SNP array. Front Genet. 2019;10:498.

30. D'Ambrosio J, Phocas F, Haffray P, Bestin A, Brard-Fudulea S, Poncet C, et al. Genome-wide estimates of genetic diversity, inbreeding and effective size of experimental and commercial rainbow trout lines undergoing selective breeding. Genet Sel Evol. 2019;51:26.

31. Ponzoni RW, Khaw HL, Nguyen HN, Hamzah A. Inbreeding and effective population size in the Malaysian nucleus of the GIFT strain of Nile tilapia (Oreochromis niloticus). Aquaculture. 2010;302:42-8.

32. do Prado FD, Vera M, Hermida M, Bouza C, Pardo BG, Vilas R, et al. Paralle evolution and adaptation to environmental factors in a marine flatfish: implications for fisheries and aquaculture management of the turbot (Scophthalmus maximus). Evol Appl. 2018;11:1322-41.

33. García de León FJ, Chikhi L, Bonhomme F. Microsatellite polymorphism and population subdivision in natural populations of European sea bass Dicentrarchus labrax (Linnaeus, 1758). Mol Ecol. 1997;6:51-62. 
34. Loukovitis D, Sarropolou E, Vogiatzi E, Tsigenopoulos CS, Kotoulas G, Magoulas A, et al. Genetic variation in farmed populations of the gilthead sea bream Sparus aurata in Greece using microsatellite DNA markers. Aquac Res. 2012;43:239-46.

35. Kohlmann K, Kersten P. Genetic variability of German and foreign common carp (Cyprinus carpio L.) populations. Aquaculture. 1999;173:435-45.

36. Kohlmann K, Kersten P, Flajšhans M. Microsatellite-based genetic variability and differentiation of domesticated, wild and feral common carp (Cyprinus carpio L.) populations. Aquaculture. 2005;247:253-66.

37. Janssen $\mathrm{K}$, Chavanne $\mathrm{H}$, Berentsen $\mathrm{P}$, Komen $\mathrm{H}$. Impact of selective breeding on European aquaculture. Aquaculture. 2017:472:8-16.

38. Yoshida GM, Barriá A, Correa K, Cáceres G, Jedicki A, Cádiz MI, et al. Genome-wide patterns of population structure and linkage disequilibrium in farmed Nile tilapia (Oreochromis niloticus). Front Genet. 2019;10:745.

39. Kijas J, Elliot N, Kube P, Evans B, Botwright N, King H, et al. Diversity and linkage disequilibrium in farmed Tasmanian Atlantic salmon. Anim Genet. 2017:48:237-41.

40. Glover KA, Solberg MF, McGinnity P, Hindar K, Verspoor E, Coulson MW, et al. Half a century of genetic interaction between farmed and wild Atlantic salmon: status of knowledge and unanswered questions. Fish Fish. 2017;18:890-927.

41. Sonesson A, Ødegård J. Mating structures for genomic selection breeding programs in aquaculture. Genet Sel Evol. 2016;48:46.

42. Meuwissen THE. Maximizing the response of selection with a predefined rate of inbreeding. J Anim Sci. 1997;75:934-40.
43. Grundy B, Villanueva B, Woolliams JA. Dynamic selection procedures for constrained inbreeding and their consequences for pedigree development. Genet Res. 1998;72:159-68.

44. Bouza C, Hermida M, Pardo BG, Vera M, Fernández C, Fernández C, et al. An expressed sequence tag (EST)-enriched genetic map of turbot (Scophthalmus maximus): a useful framework for comparative genomics across model and farmed teleosts. BMC Genet. 2012;13:54.

45. Khul H, Sarropoulou E, Tine M, Kotoulas G, Magoulas A, Reinhardt R. A comparative BAC map for the gilthead sea bream (Sparus aurata L.). J Biomed Biotechnol. 2011;2011:329025.

46. Chistiakov DA, Tsigenopoulos CS, Lagnel J, Guo Y-M, Hellemans, Haley CS, et al. A combined AFLP and microsatellite linkage map and pilot comparative genomic analysis of European sea bass Dicentrarchus labrax L. Anim Genet. 2008;39:623-34.

47. Xu P, Zhang X, Wang X, Li J, Liu G, Kuang Y, et al. Genome sequence and genetic diversity of the common carp, Cyprinus carpio. Nat Genet. 2014;46:1212-9.

48. Haller BC, Messer PW. SLiM 3: forward genetic simulations beyond the Wright-Fisher model. Mol Biol Evol. 2019;36:632-7.

\section{Publisher's Note}

Springer Nature remains neutral with regard to jurisdictional claims in published maps and institutional affiliations.
Ready to submit your research? Choose BMC and benefit from:

- fast, convenient online submission

- thorough peer review by experienced researchers in your field

- rapid publication on acceptance

- support for research data, including large and complex data types

- gold Open Access which fosters wider collaboration and increased citations

- maximum visibility for your research: over 100M website views per year

At BMC, research is always in progress.

Learn more biomedcentral.com/submissions 